\title{
ĐÁNH GIÁ TÁC DỤNG CỦA BÀI THUỐC “TK1-HV” KẾT HỢP CẢNH TAM CHÂM ĐIỀU TRI Hộ̉I CHỨNG CỔ-VAI-CÁNH TAY DO THOÁI HÓA CộT SỐNG
}

TÓM TẮT.

Muc tiêu: Đánh giá kết quả của bài thuốc "TK1HV" kết hợp cảnh tam châm điều trị hội chứng cổ-vaicánh tay do thoái hóa cột sống cổ. Đối tượng nghiên cứu: Bênh nhân trên 18 tuổi được xác đinh mắc hội chứng cổ-vai-cánh tay. Phương pháp nghiên cứu: Nghiên cứu được tiến hành theo phương pháp can thiệp lâm sàng, so sánh trước và sau điều trị, có nhóm chứng. Kết quả nghiên cứu: Giảm đau VAS: giảm 64,2\% điểm lượng giá cảm giác đau theo VAS; Tăng tầm vận động cột sống cổ ở cả 4 tư thế có ý nghĩa so với thời điểm D0; Cải thiện chức năng sinh hoat hàng ngày: giảm $79,1 \%$ điểm NDI so với D0; Hiệu quả điêuu trị chung: tốt là $90 \%$; khá là $10 \%$. Tác dụng này tốt hớn so với nhóm chứng, sự khác biệt có ý nghĩa thống kê so với $p<0,01$.

Tư khóa: Y học cổ truyền, Hội chứng cổ-vai-cánh tay, TK1-HV.

\section{SUMMARY}

\section{EVALUATING THE RESULTS OF THE REMEDY "TK1-HV" COMBINING THE TRILOGY SCENE FOR NECK-SHOULDER- ARM SYNDROME CAUSED BY DEGENERATIVE CERVICAL SPINE}

Objective: Evaluating the results of the remedy "TK1-HV" combining the trilogy scene for neckshoulder-arm syndrome caused by degenerative cervical spine. Subjects: Patients over 18 years old were identified with neck-shoulder-arm syndrome. Method: The study was conducted according to the clinical intervention method, before and after treatment, with control group. Results: VAS analgesia: $64.2 \%$ reduction in sensory assessment score. pain according to VAS; Increased range of movement of the cervical spine in all 4 postures significantly compared to the time of D0; Improve daily living function: reduce $79.1 \%$ of NDI points compared to D0; Overall therapeutic effect: good was $90 \%$; Pretty $10 \%$. This effect was better than the control group, the difference was statistically significant compared with $\mathrm{p}<0.01$.

Keywords; Traditional medicine; Neck-shouderarm syndrom; TK1-HV

\section{I. ĐĂT VẤN ĐỀ}

Hội chứng cổ-vai-cánh tay là một nhóm các triệu chứng lâm sàng liên quan đến các bệnh lý

${ }^{1}$ Bệnh viện Y học cổ truyền Bộ công an Chịu trách nhiệm chính: Phạm Bá Tuyến Email: Tuyenmai66@yahoo.com.vn Ngày nhận bài: 26.10.2020 Ngày phản biên khoa họ: 27.11.2020 Ngày duyệt bài: 9.12.2020

\section{Phạm Bá Tuyến ${ }^{1}$, Đỗ Văn Đình ${ }^{1}$}

côt sống cổ có kèm theo các rối loạn chức năng rể, dây thần kinh cột sống cổ và/hoặc tủy cổ, không liên quan tới bệnh lý viêm [1], [2].

Nghiên cứu dịch tễ học được biết đến nhiều nhất là điều tra từ năm 1976 đến năm 1990 tại Rochester, Minnesota cho thấy tỷ lệ mắc hàng năm là 107,3 trên 100.000 đối với nam và 63,5 trên 100.000 đối với nữ [3]. Nghiên cứu khác trên quân đội Hoa Kỳ từ năm 2000 đến 2009 báo cáo tỷ lệ mắc hội chứng cổ-vai-cánh tay là 1,79 trên 1.000 người mối năm [4].

Theo Y học cổ truyền (YHCT), hội chứng cổvai-cánh tay được xếp vào phạm vi Chứng tý đã được mô tả rất rõ ràng trong các y văn cổ. Nguyên nhân do phong, hàn, thấp tà xâm nhập vào cơ thể nhân khi chính khí hư suy, làm khí huyết vận hành trong kinh lạc bị trở trệ không thông mà sinh bệnh.

Cảnh tam chẩm là trường phái châm cứu của Giáo sư Cân Thụy (靳瑞) - Đại học Trung y dược Quảng Châu sáng lập [5]. Đây là phương pháp châm cứu chọn 3 huyệt dựa trên nguyên tắc phối hợp giữa huyệt tại chỗ với huyệt theo kinh, mối liên hệ giữa tạng phủ với kinh lạc, khí huyết [6]. Phương pháp này đã được tổ hợp thành 42 loại và đã ứng dụng thành công trên lâm sàng (tị, nhãn, nhĩ, thiệt, trí, não, nhiếp, nhiếp thượng, xoa, đột, cảnh (cổ), bối, kiên, thủ, túc, yêu, tất, hòa, ủy, hạt, nhũ, vị, trường, đởm, niệu, chi, phì, nhàn, âm, dương, bế, thoát tam châm, tứ thần châm, định thần châm, vựng thống châm, diện cơ châm, diện than châm, thủ trí châm, tọa cốt châm, túc trí châm, khởi bế châm, lão ngai châm). Xuất phát từ thực tiễn lâm sàng đó, cùng với mong muốn góp phần nâng cao hiệu quả điều trị, chúng tôi tiến hành nghiên cứu đề tài "Đánh giá tác dụng của bài thuốc "TK1-HV" kêt hợp cảnh tam châm điều trị hội chứng cồ-vai-cánh tay do thoái hóa cột sống" với mục tiêu sau: Đánh giá kêt quả của bài thuốc "TK1-HV" kêt hợp cảnh tam châm điều trị hôi chứng cồ-vai-cánh tay do thoái hóa cốt sông cố.

II. ĐỐI TƯợNG VÀ PHƯƠNG PHÁP NGHIÊN CứU

2.1. Địa điểm, thời gian, đối tượng nghiên cứu

- Địa điểm nghiên cứu: Bệnh viện Y học cổ truyền Bộ công an. 
- Đối tượng nghiên cứu: Bệnh nhân trên 18 tuổi được xác định mắc hội chứng cổ-vai-cánh tay.

- Thời gian nghiên cứu: Nghiên cứu được thực hiện từ 10/2018 - 8/2019

\subsection{Phương pháp nghiên cứu}

2.2.1. Thiết kế nghiên cứu. Nghiên cứu được tiến hành theo phương pháp can thiệp lâm sàng, so sánh trước và sau điều trị, có nhóm chứng.

2.2.2. Cỡ mẫu và phương pháp chọn mẫu

- Cỗ mẫu:

$\mathrm{N}=\frac{Z_{\left(1-{ }^{\alpha}{ }_{2} \times\right.} \times \overline{2 \mu(1-\mu)}+Z_{\beta} \times \overline{\overline{\mu_{1} \times 1-\mu_{1}+\mu_{2} \times\left(1-\mu_{2}\right)}}}{\left(\mu_{1}-\mu_{2}\right)^{2}}$

[7], [8]. Thay vào công thức ta được cõ mẫu là 23 bệnh nhân.

2.3. Các kỹ thuật sử dụng trong nghiên cứu

- Công cụ điện châm và kỹ thuật điện châm: Máy điện châm M8, kim châm cứu dùng 1 lần, bông, cồn 70 độ, pank có mấu, khay quả đậu.

\section{KẾT QUẢ NGHIÊN CỨU}

- Công cụ và kỹ thuật đánh giá mức độ đau theo thang điểm VAS: Mức độ đau của bệnh nhân được đánh giá theo thang điểm VAS từ 1 đến 10 bằng thước đo độ của hãng Astra- Zeneca

- Công cụ và kỹ thuật đo tâm vận động cột sống cổ: Thước đo tâm vận động cột sống.

- Công cụ đánh giá mức độ hạn chế sinh hoạt hàng ngày

2.4. Chất liệu nghiên cứu

- Bài thuốc TK1-HV

- Phác đồ huyệt Cảnh tam châm

- Phác đồ huyệt điện châm

2.5. Phương pháp xử lý số liệu. Số liệu sau thu thập được xử lý bằng thuật toán thông kê y sinh học dưới sự hỗ trợ của phần mềm SPSS 20.0 của IBM. Thuật toán được sử dụng bao gôm: đếm số lượng, tính tỷ lệ \%, kiểm định Ttest, khi bình phương. Với mức ý nghĩa 95\%, kết quả có ý nghĩa thống kê với $p<0,05$.

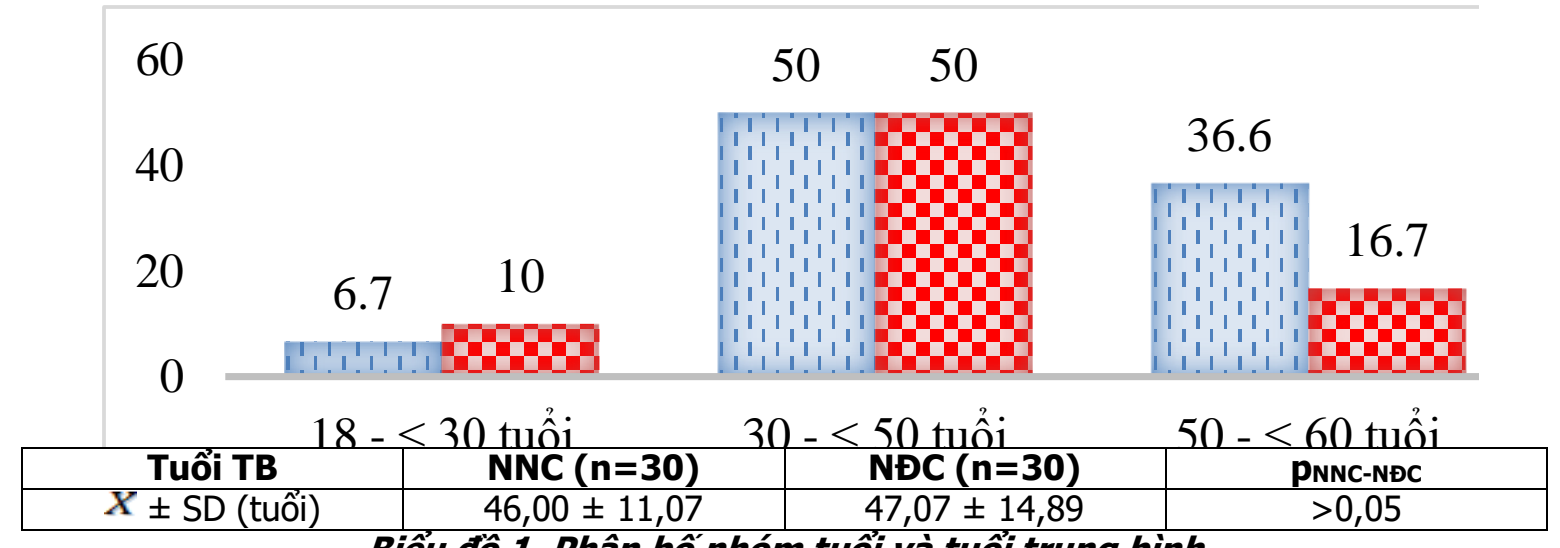

Biếu đồ 1. Phân bố nhóm tuối và tuối trung binh

Hầu hết bênh nhân đều ở nhóm tuổi từ $30-<50$ tuổi (tỷ lệ bằng nhau và bằng $50 \%$ ở cả NNC và NĐC); thấp nhất ở nhóm từ 18 - < 30 tuổi. Tuổi TB là 46,00 $\pm 11,07$ (tuổi) ở NNC và 47,07 \pm 14,89 (tuôii) $(p>0,05)$

\section{Bảng 1. Sự thay đổi mức độ đau theo VAS trước-sau điều trị}

\begin{tabular}{|c|c|c|c|c|c|c|c|}
\hline \multirow{2}{*}{$\begin{array}{c}\text { Mức độ đau VAS } \\
(\mathbf{n}, \%)\end{array}$} & \multicolumn{3}{|c|}{$\operatorname{NNC}(n=30)$} & \multicolumn{3}{|c|}{$\operatorname{NDC}(n=30)$} & \multirow[b]{2}{*}{ PNNC-NEC } \\
\hline & $\mathrm{D}_{0}$ & $D_{14}$ & $\mathrm{D}_{2}$ & $\mathrm{D}_{0}$ & $\mathrm{D}_{14}$ & & \\
\hline Không đau (0 điểm) & $0(0)$ & & & & 0( & & \\
\hline & & & & & & & \\
\hline & 88033 & $19(63$, & $5(16,7)$ & $27(90,0)$ & $23(76,6)$ & $15(50,0)$ & $\mathrm{p}_{228}<0,05$ \\
\hline
\end{tabular}

- Không có sự khác biệt có ý nghĩa thống kê về mức độ đau giữa NNC và NĐC tại thời điểm trước điều trị.

- Tại thời điểm sau 14 ngày điều trị: Tỷ lệ bệnh nhân ở mức đau vừa giảm, đau nhẹ tăng, sự khác biệt không có ý nghĩa thống kê giữa NNC và NĐC.

- Tại thời điểm sau 28 ngày điều trị: Tỷ lệ bệnh nhân không đau ở NNC là $10 \%$; đau nhe là $73,3 \%$; đau vừa là $16,7 \%$; NĐC không đau là 3,3\%; đau nhẹ là $46,7 \%$ và đau vừa là $50 \%$; sự khác biệt có ý nghĩa thống kê giữa hai nhóm.

\section{Bảng 2. Sự thay đối giá trị TB điểm đau VAS trước và sau điều trị}

\begin{tabular}{|c|c|c|c|}
\hline Thời điểm & NNC $(\mathbf{n}=\mathbf{3 0})$ & NĐC $(\mathbf{n}=\mathbf{3 0})$ & PNNC-NĐC \\
\hline$D_{0}$ & $4,90 \pm 2,11$ & $4,67 \pm 2,06$ & $>0,05$ \\
\hline
\end{tabular}




\begin{tabular}{|c|c|c|c|}
\hline $\mathrm{D}_{14}$ & $2,98 \pm 1,21$ & $3,68 \pm 1,45$ & $>0,05$ \\
\hline $\mathrm{D}_{14}-\mathrm{D}_{0}$ & $1,27 \pm 0,40$ & $0,97 \pm 0,56$ & $<0,05$ \\
\hline $\mathrm{D}_{28}$ & $1,96 \pm 0,78$ & $3,05 \pm 0,67$ & $<0,01$ \\
\hline $\mathrm{D}_{28}-\mathrm{D}_{0}$ & $2,88 \pm 1,15$ & $1,03 \pm 0,81$ & $<0,01$ \\
\hline
\end{tabular}

Hiệu số điếm đau VAS giữa NNC và NĐC tại thời điếm sau 14 ngày và 28 ngày điều trị khác biệt có ý nghĩa thống kê với $\mathrm{p}<0,01$.

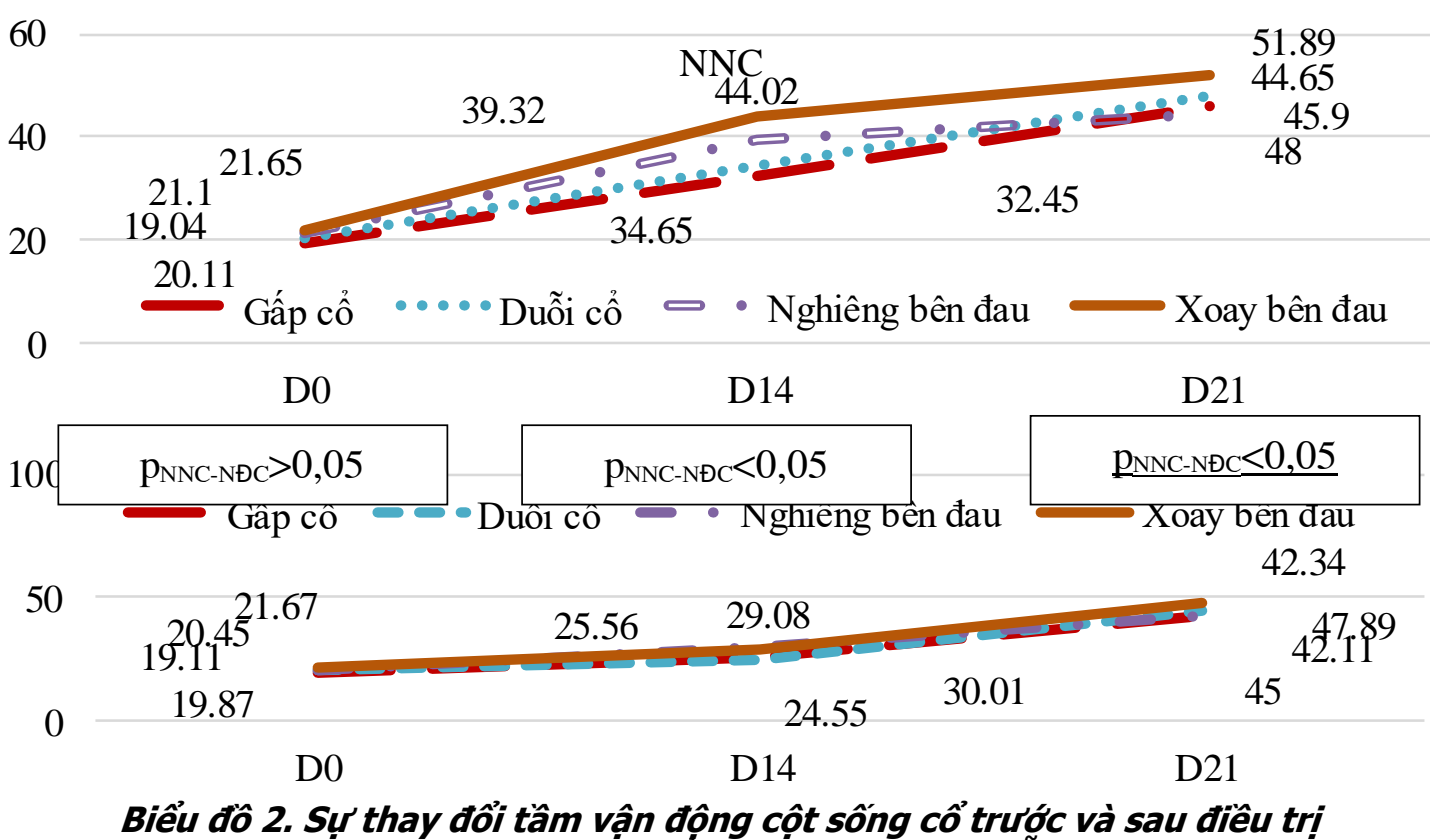

Nhận xét: Biên độ vận động của cột sống cổ ở các tư thế gập, duỗi, nghiêng và xoay có sự khác biệt có ý nghĩa thống kê giữa NNC và NĐC tại các thời điểm theo dõi ( $p>0,05)$.

Bảng 2. Sự thay đổi điểm NDI trước và sau điều trị

\begin{tabular}{|c|c|c|c|}
\hline Thời điểm theo dõi & NNC $(n=30)$ & NĐC $(n=30)$ & PNNC-NDC \\
\hline $\mathrm{D}_{0}$ & $21,67 \pm 5,78$ & $21,00 \pm 4,56$ & $>0,05$ \\
\hline $\mathrm{D}_{14}$ & $10,78 \pm 2,89$ & $14,12 \pm 2,11$ & $<0,05$ \\
\hline$D_{28}$ & $4,50 \pm 1,07$ & $7,78 \pm 1,99$ & $<0,01$ \\
\hline Pcác thời điểm theo dõi & $\begin{array}{l}\text { PD0-D14 }_{2}<0,05 ; \\
\text { p}_{\text {D0-D28 }}<0,01\end{array}$ & $\begin{array}{l}\text { PD0-D14 }_{\text {D }}<0,05 ; \\
\text { PD0-D28 }_{0}<0,01\end{array}$ & \\
\hline
\end{tabular}

Điếm trung bình NDI có sự khác biệt tại các thời điếm nghiên cứu ở cả NNC và NĐC $(p<0,05)$, trong đó, NNC tốt hơn NĐC ( $p<0,01)$. 

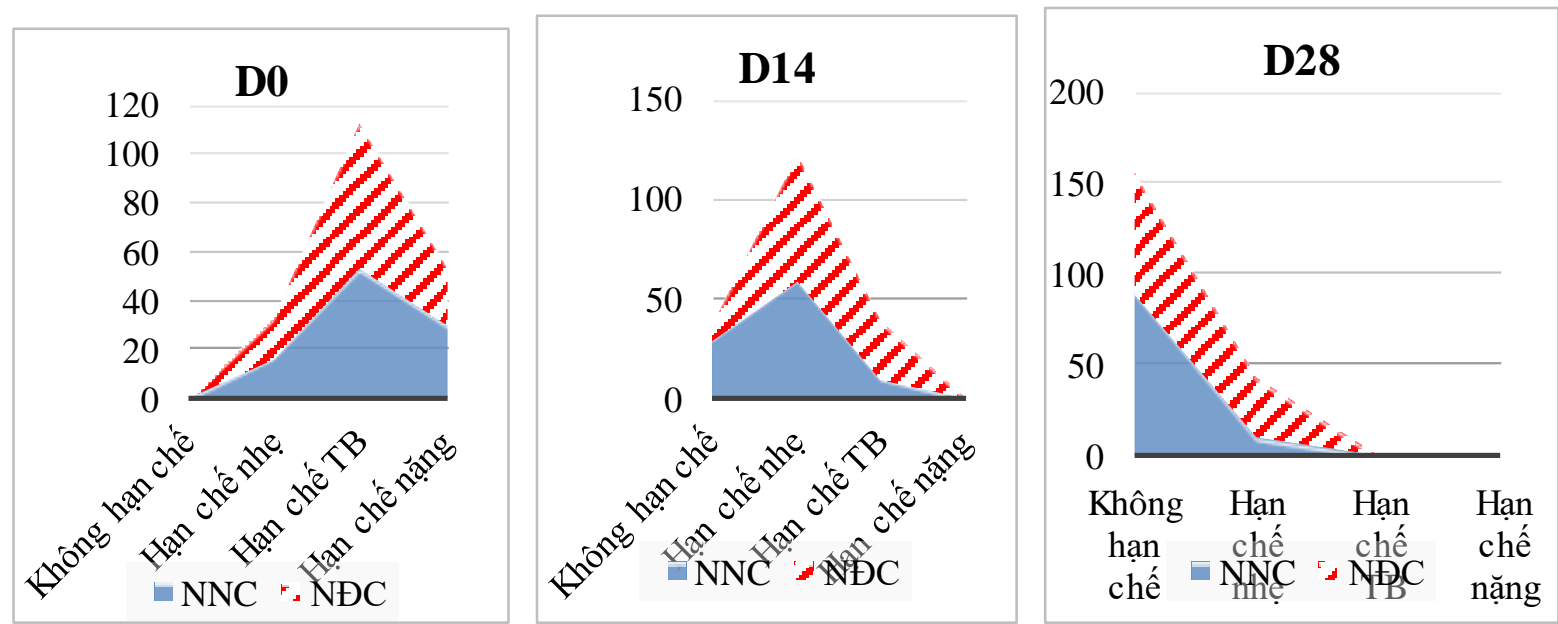

Biểu đồ 3. Sự thay đổi phân loại điểm NDI trước và sau điều trị

Mức độ hạn chế chức năng sinh hoạt hoàng ngày vùng cột sống cổ có sự cải thiện rõ rệt ở cả NNC và $\mathrm{NĐC} \mathrm{(} p<0,05$ tại các thời điểm quan sát), trong đó, NNC tốt hơn $\mathrm{NĐC}(p<0,01)$.

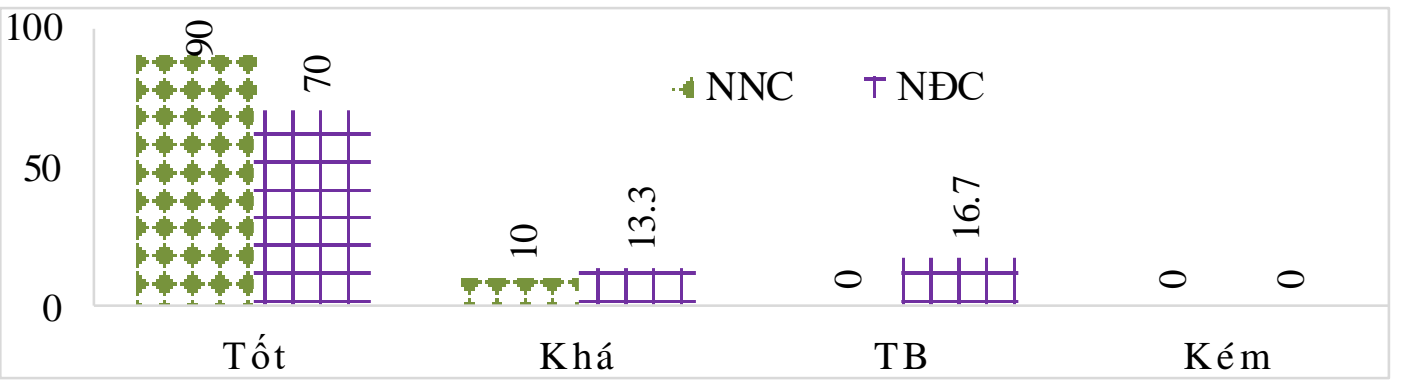

Biểu đồ 4. Hiệu quả điều trị chung

Sau 28 ngày can thiệp, tỷ lệ bệnh nhân đạt mức Tốt ở NNC cao hơn NĐC, không còn bệnh nhân nào mức kém. Sự khác biệt có ý nghĩa thống kê giữa NNC và $N Đ C(p<0,01)$.

\section{BÀN LUẦN}

Về tuổi và nhóm tuổi, bên cạnh yếu tố dịch tễ học của bệnh lý, do địa bàn nghiên cứu là Bệnh viện YHCT Bộ công an, nơi hàng năm tiếp nhận một lượng lớn bệnh nhân là cán bộ ngành và nhân dân địa phương, do đó, tuổi TB của bệnh nhân trong nghiên cứu khá cao (46-47 tuổi ở cả NNC và NĐC - biểu đồ 3.1) với phân bố ở nhóm 30 - 50 tuổi chiếm 50\% đối tượng mắc hội chứng cổ-vai-cánh tay. Điều này một phần được lý giải bởi những những biến đổi về hình thái các đốt sống cổ - nguyên nhân gây thoái hóa dẫn đến hội chứng cổ-vai-cánh tay gây ra các triệu chứng lâm sàng, cận lâm sàng điển hình thường xuất hiện khi bệnh nhân bước vào tuổi trung niên, một phần là bởi đặc thù địa lý của đơn vị tiến hành nghiên cứu - điều này đồng thời cũng làm ảnh hưởng đến chất lượng cuộc sống và hiệu quả lao động, khiến bệnh nhân phải nhập viện điều trị. Kết quả nghiên cứu của chúng tôi khá tương đồng với nghiên cứu của Kanishka $\mathrm{E}$ Williams [9].

Trong nghiên cứu của chúng tôi, điểm đánh giá đau VAS được phân thành hai mảng rõ rệt, một là phân loai điểm đau VAS theo các mức đố từ không đau đến đau trung bình, và thứ hai là điểm trung bình VAS tại các thời điểm nghiên cứu. Kết quả về sự cải thiện cho thấy, ở cả hai nhóm can thiệp đều có mức giảm của cả trị số trung bình và thay đổi mức độ đau rõ với $p<0,05$ tại tất cả các thời điểm quan sát. Bởi việc lựa chọn bệnh nhân có VAS $<6$ điểm, là những bệnh nhân có ngưỡng đau ở mức độ vừa phải, do đó, trong quá trình đánh giá, chúng tôi không ghi nhận được trường hợp nào mức độ đau tiến triển nặng hơn so với thời điểm trước điều trị. Hầu hết bệnh nhân đều giảm đau, đưa ngưỡng phân loại đau theo thang nhìn VAS từ đau vừa hoặc đau nhe về không đau, trong đó NNC có sự cải thiện tốt hơn NĐC (bảng 3.1). Mặc dù sự cải thiện mức đau về không đau chưa thực sự rõ 
ràng (3/30 bệnh nhân NNC và $1 / 30$ bệnh nhân

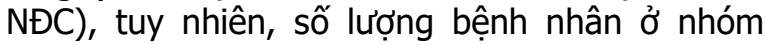
đau vừa (giảm 1 ngưỡng đau) lại tăng lên đáng kể (22/30 ở NNC và 14/30 ở NĐC), cùng với đó là ngưỡng điểm đau có sự thay đổi rõ rệt từ 4,90 xuống còn 1,96 (hiệu số giảm điểm là 2,88 điểm ở NNC) và 4,67 điểm xuống còn 3,05 điểm (hiệu số giảm điểm là 1,03 ở NĐC) (bảng 3.2). Kết quả này cũng cho thấy sự cải thiện về hiệu số điểm đau ở NNC là tốt hơn NĐC. Kết quả có ý nghĩa thống kê với $p<0,01$. Hiệu quả lâm sàng này tương ứng với kết quả nghiên cứu thực nghiệm trước đó đã được tiến hành để chứng minh tác dụng dược lý của thuốc: Tác dụng giảm đau của cao lỏng TK1-HV được đánh giá trên mô hình gây đau tại tổ chức viêm (Randall-Selitto Test), mô hình gây đau quặn (Writhing Tests), và mô hình phiến nóng (Hot plate test). Mô hình gây đau tại tổ chức viêm (Randall-Selitto Test) và mô hình gây đau quăn (Writhing Tests) là hai mô hình dược lý cơ bản, được sử dụng rộng rãi nhất để đánh giá tác dụng giảm đau ngoại vi của thuốc, đặc biệt đau do viêm. Mô hình "phiến nóng" (Hot plate test) cho phép đánh giá tác dụng giảm đau trung ương của cao lỏng. Cao lỏng TK1-HV thể hiện rõ cả tác dụng giảm đau ngoại vi (trong thử nghiệm Randall-Selitto Test và Writhing Tests), và cả tác dụng giảm đau trung ương (trong thử nghiệm Hot plate test). Tác dụng giảm đau ngoại vi có thể do cơ chế ức chế các prostglandin và các chất trung gian hóa học khác như histamin, bradykinin, đồng thời có vai trò của tác dụng chống viêm làm giảm phù nề, chèn ép. Tác dụng giảm đau trung ương có thể có vai trò của tác dung bổ huyết, dưỡng huyết an thần của kê huyết đằng, hà thủ ô.

Trong nghiên cứu này, chúng tôi đã tiến hành đo góc và phân loại tầm vận động cột sông cổ ở 4 động tác: gấp cổ, duỗi cổ, nghiêng bên đau, xoay bên đau theo phương pháp Zero. Số liệu thể hiện ở biểu đồ 3.2 cho thấy biên độ vần động của cột sống cổ ở các tư thế gập, duối, nghiêng, xoay ở cả nhóm nghiên cứu và nhóm đối chứng tại các thời đều tăng so với trước điều trị. Cụ thể:

- Ở nhóm nghiên cứu, biên độ vận động ở các tư thế gấp/duỗi/nghiêng/xoay tại thời điểm trước nghiên cứu lần lượt là 20,01/ 19,04/21,1/ 21,65 ; sau 14 ngày điều trị mức độ này tăng lên lần lượt là $32,45 / 34,65 / 39,32 / 44,02$, và đên thời điểm 28 ngày sau điều trị biên độ của các động tác này tăng gấp hơn 2 lần so với trước điều trị: $45,49 / 44,65 / 48 / 51,89$.
- Ở nhóm đối chứng, biên độ vận động ở các tư thế gấp/duỗi/nghiêng/xoay tại thời điểm trước nghiên cứu lần lượt là 19,87/19,11/20,45/21,67; sau 14 ngày điêu trị mức độ này tăng lên lần lượt là $24,55 / 25,56 / 29,08 / 30,01$. Đến thời điểm 28 ngày sau điều trị biên độ của các động tác này tăng lần lượt là 45/42,11/42,34/47,89.

Về phân loại, trước điều trị $100 \%$ bệnh nhân ở cả hai nhóm đều bị hạn chế tầm vận động.

- Ở nhóm nghiên cứu, tầm vận động bị hạn chễ mức độ nhẹ chiếm 13,3\%, hạn chế trung bình chiếm $76,7 \%$ và hạn chế nhiêu là $10 \%$;

Sau 14 ngày điều trị, có sự cải thiện tầm vận động cột sống cổ ở cả hai nhóm bệnh nhân.

- Ở nhóm nghiên cứu, mức độ hạn chế nhẹ / trung bình lần lượt là $63,3 \% / 6,7 \%$ không còn bệnh nhân nào bị hạn chế tầm vận động nhiề;

- Ở nhóm đối chứng, mức độ bệnh nhân bị hạn chế nhẹ/trung bình lần lượt là 73,3\%/ 16,7\%, không còn bệnh nhân nào bị hạn chế tầm vận động nhiều. Sự khác biệt có ý nghĩa thống kê khi so sánh trước và sau điều trị 14 ngày với $p<0,05$, tác dụng cải thiện tầm vận động của hai phương pháp sau 14 ngày là tương tự nhau.

Mục tiêu điêu trị hội chứng cổ-vai-cánh tay, bên cạnh việc giảm đau, tăng tầm vận động cột sống, một mục tiêu nữa cần hướng tới là nâng chất lượng cuộc sống, tăng cường hòa nhập lại với sinh hoạt hàng ngày của bệnh nhân, thông qua việc giảm, hạn chế các hoạt động cá nhân không thực hiện được do đau. Do đau và hạn chế tầm vận động cột sống ở bệnh nhân hội chứng cổ-vai-cánh tay do thoái hóa cột sống cổ nên việc thực hiện các hoạt động sinh hoạt hàng ngày như: tắm, mặc quần áo, đọc sách báo, lái xe, ngủ, làm việc... bị ảnh hưởng. Để đánh giá mức độ hạn chế hoạt động sinh hoạt hàng ngày chúng tôi sử dụng bộ câu hỏi Neck Disability Index (NDI) của tác giả Howard Vernon. Bộ câu hỏi NDI được công bố lần đầu vào năm 1991 và là bô câu hỏi đầu tiên cho viêc tự đánh giá mức độ hạn chế gây ra do đau cổ gáy, đã được dịch ra 20 ngôn ngữ và sử dụng rộng rãi trong nghiên cứu điều trị. Bộ câu hỏi NDI gồm 10 mục: cường độ đau, sinh hoạt cá nhân (tắm, mặc quần áo...), nâng đồ vật, đọc (sách, báo...), đau đầu, khả năng tập trung chú ý, làm việc, lái xe, ngủ và các hoạt động giải trí. Mỗi mục tối đa 5 điểm và tối thiểu 0 điểm, bệnh nhân được hướng dẫn trả lời theo bảng câu hỏi có sẵn. Điểm NDI là tổng điểm của 10 mục trên và được phân thành các mức độ từ không hạn chế đến hạn chế nặng. Phương pháp này đơn giản, thuận tiện cho quá 
trình nghiên cứu, tuy nhiên nó phụ thuộc vào tính chủ quan của mỗi bệnh nhân.

Trong nghiên cứu của chúng tôi, sự thay đổi điểm chức năng sinh hoạt hàng ngày vùng cột sống cổ của bệnh nhân qua bảng 3.2 và biểu đồ 3.3 cho thấy, mức độ hạn chế có sự cải thiện đáng kể qua các thời điểm nghiên cứu, trong đó, NNC tốt hơn NĐC. Tỷ lê bênh nhân han chế năng giảm dần, không hạn chế tăng dần, điểm TB NDI cũng có sự cải thiện đáng kể tại thời điểm sau 14 ngày và 28 ngày can thiệp.

Về phân bố hiệu quả điều trị chung, chúng tôi chỉ tiến hành đánh giá tại thời điểm kết thúc nghiên cứu - tương ứng với 28 ngày điều trị liên tục bằng bài thuốc TK1-HV kết hợp cảnh tam châm với NNC và điện châm đối với NĐC. Tỷ lệ hiệu quả tốt đạt tới 90\% ở NNC và 70\% ở NĐC. Tỷ lệ hiệu quả khá là $10 \%$ ở NNC và $13,3 \%$ ở NĐC. Hiệu quả TB là $16,7 \%$ ở NĐC. Không có bệnh nhân nào ở mức kém. Như vậy, NNC sau 28 ngày điều trị, hiệu quả tốt và khá đạt $100 \%$; NĐC đạt 83,3\% (biểu đồ 3.4).

\section{KẾT LUÂN}

- Giảm đau VAS: giảm 64,2\% điểm lượng giá cảm giác đau theo VAS;

- Tăng tầm vận động cột sống cổ ở cả 4 tư thế có ý nghĩa so với thời điểm D0;

- Cải thiện chức năng sinh hoạt hàng ngày: giảm $79,1 \%$ điểm NDI so với D0;

- Hiệu quả điêu trị chung: tốt là 90\%; khá là 10\%.

- Tác dụng này tốt hơn so với nhóm chứng, sự khác biệt có ý nghĩa thống kê so với $p<0,01$.

\section{KHUYẾN NGH!}

- Nghiên cứu phương pháp cảnh tam châm trên số lượng bệnh nhân lớn hơn, tại một số cơ sở điều trị khác.

- Đánh giá tác dụng độc lập của phương pháp cảnh tam châm trên lâm sàng.

\section{TÀI LIÊU THAM KHẢO}

1. Bộ Y tế (2016). Hướng dẫn chẩn đoán và điều trị các bệnh cơ xương khớp, Nhà xuất bản Y học, Hà Nội, 145-153.

2. Caridi J.M., Pumberger M., Hughes A.P. (2011). Cervical radiculopathy: a review, HSS J Musculoskelet J Hosp Spec Surg, 7(3), pg 265-272.

3. Radhakrishnan K., Litchy W.J., O'Fallon W.M. et al (1994). Epidemiology of cervical radiculopathy. A population-based study from rochester, minnesota, 1976 through 1990, Brain, 117, pg 325-335.

4. Schoenfeld A.J, George A.A., Bader J.O. et al (2012). Incidence and epidemiology of cervical radiculopathy in the united states military: 2000 to 2009, J Spinal Disord Tech, 25, pg 17-22.

5. 75. Liao W., Tang C., Zhang J. (2018). Discussion on the principle and treatment pathway of Jin's three-needle technique for mind regulation and treatment from the "Adjusting qi to regulate mind, adjusting blood to regulate mind", Zhongguo Zhen Jiu, 38(11), pg 1235-1238.

6. Yuan Qing, Luo Guangming, Jeffrey Winsauer et al (2004). Chinese-English explanation of Jin' 3-needle technique, Shanghai Scientific and technologicl Literature publishing house ${ }_{2}$ China.

7. Nguyến Văn Tuấn (2008). Y học thực chứng, Nhà xuất bản Y học, Hà Nội, 90.

8. Lưu Ngọc Hoat (2018). Phương pháp viết đề cương nghiên cửu khoa học, Nhà xuất bản $Y$ học, Hà Nổi.

9. Williams K.E., Paul R., Dewan Y. (2009). Functional outcome of corpectomy in cervical spondylotic myelopathy, Indian J Orthop, 43(2), 205-209. 